\title{
A CONCORDÂNCIA E O USO DO CLÍTICO SE COMO PARTÍCULA APASSIVADORA NO PORTUGUÊS POPULAR DE LUANDA
}

\author{
Maike da Silva Pereira ${ }^{1}$; Silvana Silva de Farias Araujo ${ }^{2}$ \\ 1. Bolsista PIBIC/CNPq, Graduando em Letras com Inglês, Universidade Estadual de Feira de Santana, e-mail: \\ maike.js@hotmail.com \\ 2. Professora Dra Silvana Silva de Farias Araujo, Departamento de Letras e Artes, Universidade Estadual de Feira de \\ Santana, e-mail: silvana.uefs.2014@gmail.com
}

PALAVRAS-CHAVE: Clítico se; português popular angolano; português brasileiro.

\section{INTRODUÇÃO}

Os estudos que envolvem o clítico se têm despertado questões importantes e que merecem ser discutidas. Nas mais diversas áreas da linguística, pesquisadores têm explicitado o conservadorismo presente em estudos gramaticais na classificação do clítico se ora como índice de indeterminação do sujeito, ora como partícula apassivadora. Esse ceticismo presente nas abordagens prescritivas da língua tem como consequência o afastamento dos falantes da língua, pois construções comumente vistas na norma popular do português, como "Vende-se casas" acabam sendo classificadas erroneamente como "agramaticais" pela tradição gramatical.

É nesse ponto que os estudos linguísticos, sociolinguísticos e filológicos têm contribuído para um olhar mais delicado acerca das contradições presentes na tradição gramatical sobre o uso do se. Este plano baseia-se na observação e análise do português de variedade africana (PA) falado por luandenses, pautando-se ora em pesquisas anteriores sobre concordância verbal com a terceira pessoa do plural, ora em pesquisas sociolinguísticas sobre o uso do clítico se no português brasileiro (PB). O intuito aqui estabelecido é de pesquisar se o fenômeno da concordância padrão na terceira pessoa do singular, que se mostrou tão presente em pesquisas anteriores sobre o português de variedade angolana, interfere no uso do clítico se nas entrevistas analisadas. Já que, segundo a tradição gramatical, para a realização do clítico se como partícula apassivadora é imprescindível que haja concordância verbal.

\section{MATERIAL E MÉTODOS OU METODOLOGIA (ou equivalente)}

Considerando a relação entre língua e sociedade e a heterogeneidade presente em comunidades linguísticas, consideraremos o modelo teórico-metodológico a Sociolinguística Variacionista, modelo proposto inicialmente por William Labov (2008[1972]. A metodologia empregada no trabalho consistirá de uma análise sociolinguística, por meio de análise quantitativa e qualitativa dos dados sobre a concordância verbal com a terceira pessoa e o uso do clítico se como partícula apassivadora. Para isso, contamos com um corpus de entrevistas gravadas em Luanda. Tais entrevistas constam de diálogos entre informante e entrevistador (DID), gravadas com o auxílio de gravador portátil e fichas de cadastramento dos informantes e dos dados. Porém, com o decorrer da pesquisa a quantidade de dados do uso do se como 
partícula apassivadora foi pequeno, então a pesquisa centrou-se em pesquisar e descrever a variação da concordância verbal da terceira pessoal com o uso do se como apassivadora, índice de indeterminação de sujeito, pronome oblíquo reflexivo e recíproco, e como parte integrante de verbos pronominais.

\section{RESULTADOS E/OU DISCUSSÃO (ou Análise e discussão dos resultados)}

Foram obtidos 90 dados nas entrevistas transcritas do português popular de Angola, o gráfico abaixo ilustra a frequência dos dados de acordo com o uso do clítico "se":

\section{Uso do clítico se no corpus}

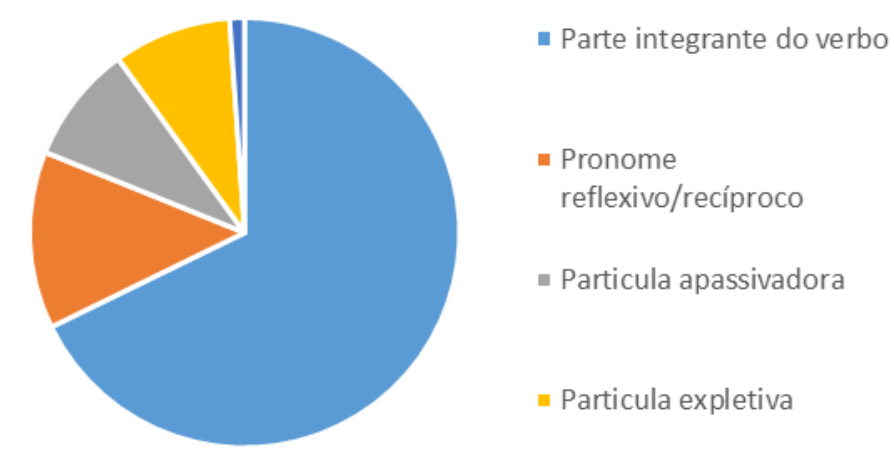

- Indice de indeterminação

Gráfico I: Categorização gramatical do uso do clítico se encontrada no corpus da pesquisa

Das 90 ocorrências encontradas, 62 (62/90) se enquadraram na categoria de parte integrante do verbo, o que corresponde a mais da metade do gráfico. Em seguida, constam 11 casos do clítico se como pronome oblíquo recíproco ou pronome oblíquo reflexivo, mesmo sendo a segunda categoria com mais casos, se compararmos com os casos em que o se foi encontrado em verbos pronominais, esse número corresponde a um total bastante inferior (11/90). Com pouco menos, os casos de partícula apassivadora e partícula de realce aparecem na sequência totalizando 8 casos cada (8/90) - há casos de construções em que o se figura como partícula apassivadora e 8 casos em que se caracteriza como partícula de realce (ou partícula expletiva) não sendo relevante para o entendimento do período, juntos somam 16 casos. A categoria com menos casos datados foi a do se como índice de indeterminação do sujeito, contando apenas com um caso (1/90). A variável de concordância verbal foi observada ao longo da pesquisa. A partir da análise dos usos do se encontrados no corpus, ressaltamos que os casos em que o se figura como partícula de realce foram suprimidos da tabela a seguir, pois, quando desempenha essa função, o se não tem nenhuma função gramatical dentro do período. Em todas as 8 ocorrências do se como partícula expletiva presentes no corpus o verbo se apresenta em modo infinitivo. Foi observado se as outras 82 ocorrências encontradas e categorizadas em consequência da função do se dentro do período apresentavam concordância verbal padrão ou concordância verbal não-padrão. 
Reforçando que foram encontrados dados em que constava o uso do clítico se com a primeira pessoa do singular e plural e não somente interagindo com a terceira pessoa, apresentamos as seguintes constatações acerca da concordância verbal:

\begin{tabular}{|c|c|c|c|}
\hline & $\begin{array}{c}\text { Concordância } \\
\text { padrão }\end{array}$ & $\begin{array}{l}\text { Concordância não- } \\
\text { padrão }\end{array}$ & TOTAL \\
\hline $\begin{array}{c}\text { Partícula } \\
\text { apassivadora }\end{array}$ & 5 & 3 & 8 \\
\hline $\begin{array}{c}\text { Índice de } \\
\text { indeterminação }\end{array}$ & 1 & 0 & 1 \\
\hline $\begin{array}{c}\text { Parte integrante do } \\
\text { verbo }\end{array}$ & 52 & 10 & 62 \\
\hline $\begin{array}{c}\text { Pronome obliquo } \\
\text { reflexivo }\end{array}$ & 9 & 2 & 11 \\
\hline Resultado & 67 & 15 & 82 \\
\hline
\end{tabular}

\section{CONSIDERAÇÕES FINAIS (ou Conclusão)}

Subtraindo do total de 90 casos os 8 casos de partícula expletiva, temos um total de 82 casos, resultando em um percentual de $82,5 \%$ de realização da concordância verbal padrão em terceira pessoa pelos falantes da variedade angolana do português. Ou seja, mesmo que os informantes luandenses se confundam acerca do uso do clítico se, a variedade angolana do português ainda se mostra muito próxima ao português europeu (PE). Em pesquisa anterior acerca do uso do clítico se em textos escritos luandenses, obtivemos um percentual total de 94,1\% de concordância verbal padrão com a terceira pessoa - foram encontrados 222 ocorrências do uso do clítico se como apassivador. Diante desses dois percentuais obtidos nos dois eixos concluímos que mesmo que no português popular falado em Luanda não haja tantas ocorrências do uso do clítico se como apassivadora como há nos jornais escritos e redações de pré-vestibulandos, os falantes obedecem às normas gramaticais de uso.

\section{REFERÊNCIAS}

ARAUJO, Silvana Silva de Farias. A concordância verbal e sua importância para os estudos sobre a formação do português brasileiro. Papia (Brasília), v. 22(1), p. 91-110, 2012.

ARAUJO, Silvana Silva de Farias. Concordância verbal e formação da realidade sociolinguística brasileira. Cuadernos de la ALFAL, v. 7, p. 144-184, 2015.

BAGNO. Marcos. Português ou brasileiro?: Um convite à pesquisa. São Paulo: Parábola Editorial, 2001.

BECHARA, Evanildo. Moderna Gramática Portuguesa. 36 ed., SP: Companhia Editora Nacional, 1997. 
CAVALCANTE, Silvia Regina de Oliveira. 1999. A indeterminação do sujeito na escrita padrão: a imprensa carioca nos século XIX XX. Dissertação de Mestrado, Faculdade de Letras/ UFRJ, Rio de Janeiro.

CUNHA, Celso \& CINTRA, L. F. L. Nova Gramática do Português Contemporâneo. 2. ed. Rio de Janeiro: Nova Fronteira, 1985.

LABOV, William. Padrões sociolinguiísticos. Tradução Marcos Bagno, Maria Marta Pereira Scherre, Caroline Rodrigues Cardoso. São Paulo: Parábola Editorial, 2008.

LUCCHESI, Dante. História do contato entre línguas no Brasil. In: LUCCHESI, Dante; BAXTER, Alan; RIBEIRO, Ilza. (Org.). O Português Afro-Brasileiro. Salvador: EDUFBA, 2009. p. 41-73.

MARTINS, Edson Ferreira. Um problema de sintaxe histórica: a descrição de construções com se apassivador/ indeterminador no português do Brasil e no português europeu. Universidade de Évora, 2011.

NUNES, J.M. O famigerado se: uma análise sincrônica e diacrônica das construções com se apassivador e indeterminador. Campinas: Unicamp, 1990. (Dissertação de mestrado.)

SANKOFF, David; TAGLIAMONTE, Sali A., e SMITH, Eric. Goldvarb X: a multivariate analysis application, Toronto, Department of Linguistics; Ottawa, Department of Mathematics. 2005.

Disponível em:<http://individual.utoronto.ca/tagliamonte/Goldvarb/GV_index.htm\#ref. Acesso em 28. mar. 2015. 